\title{
Oral co-administration of elacridar and ritonavir enhances plasma levels of oral paclitaxel and docetaxel without affecting relative brain accumulation
}

\author{
J J M A Hendrikx ${ }^{\star}, 1,2$, J S Lagas ${ }^{1}$, E Wagenaar ${ }^{2}$, H Rosing ${ }^{1}$, J H M Schellens ${ }^{3,4}$, J H Beijnen ${ }^{1,4}$ and A H Schinkel ${ }^{2}$ \\ ${ }^{1}$ Department of Pharmacy and Pharmacology, Slotervaart Hospital, PO 90440, 1006 BK Amsterdam, The Netherlands; ${ }^{2}$ Division of \\ Molecular Oncology, The Netherlands Cancer Institute, PO 90203, 1006 BE Amsterdam, The Netherlands; ${ }^{3}$ Department of Clinical \\ Pharmacology, The Netherlands Cancer Institute, PO 90203, 1006 BE Amsterdam, The Netherlands and ${ }^{4}$ Department of \\ Pharmaceutical Sciences, Utrecht University, PO 80082, 3508 TB Utrecht, The Netherlands
}

Background: The intestinal uptake of the taxanes paclitaxel and docetaxel is seriously hampered by drug efflux through P-glycoprotein (P-gp) and drug metabolism via cytochrome P450 (CYP) 3A. The resulting low oral bioavailability can be boosted by co-administration of P-gp or CYP3A4 inhibitors.

Methods: Paclitaxel or docetaxel $(10 \mathrm{mg} / \mathrm{kg})$ was administered to CYP3A4-humanised mice after administration of the P-gp inhibitor elacridar $\left(25 \mathrm{mg} \mathrm{kg}^{-1}\right)$ and the CYP3A inhibitor ritonavir $\left(12.5 \mathrm{mg} \mathrm{kg}^{-1}\right)$. Plasma and brain concentrations of the taxanes were measured.

Results: Oral co-administration of the taxanes with elacridar increased plasma concentrations of paclitaxel $(10.7$-fold, $P<0.001)$ and docetaxel (four-fold, $P<0.001$ ). Co-administration with ritonavir resulted in 2.5-fold (paclitaxel, $P<0.001$ ) and 7.3-fold (docetaxel, $P<0.001$ ) increases in plasma concentrations. Co-administration with both inhibitors simultaneously resulted in further increased plasma concentrations of paclitaxel (31.9-fold, $P<0.001)$ and docetaxel (37.4-fold, $P<0.001)$. Although boosting of orally applied taxanes with elacridar and ritonavir potentially increases brain accumulation of taxanes, we found that only brain concentrations, but not brain-to-plasma ratios, were increased after co-administration with both inhibitors.

Conclusions: The oral availability of taxanes can be enhanced by co-administration with oral elacridar and ritonavir, without increasing the brain penetration of the taxanes.

The taxane anticancer agents paclitaxel (Taxol) and docetaxel (Taxotere) share the baccatin core ring structure (Vaishampayan et al, 1999). Currently, paclitaxel and docetaxel are routinely applied intravenously (i.v.) to treat several types of cancer, such as non-small cell lung cancer, ovarian, breast, gastric, prostate and head-and-neck cancer (Gligorov and Lotz, 2004; Koolen et al, 2010a).

The development of oral formulations of paclitaxel and docetaxel is the focus of preclinical and clinical research in our groups because oral administration has many advantages over i.v. administration (Schellens et al, 2000; Koolen et al, 2010a). Oral administration is more practical and convenient for patients as oral medication can be taken by the patient at home, whereas i.v. administration requires hospitalisation during infusion. Oral administration in the home situation also reduces treatment cost. Moreover, oral administration enables other dosing schedules such as metronomic therapy (e.g., continuous or frequent treatment 
with low doses of anticancer drugs), which can increase efficacy of taxane treatment and reduce adverse effects caused by high plasma concentrations of docetaxel or paclitaxel (Jiang et al, 2010; Wu et al, 2011).

A major limitation in the concept of oral administration of taxanes is, however, the low oral availability of paclitaxel and docetaxel (Schellens et al, 2000; Koolen et al, 2010a). Paclitaxel and docetaxel have poor aqueous solubility and upon oral administration, intestinal uptake is seriously hampered by drug efflux through $\mathrm{P}$-glycoprotein (P-gp/MDR1/ABCB1), and systemic exposure is further limited by drug metabolism via cytochrome P450 (CYP) 3A (Sparreboom et al, 1997; van Asperen et al, 1997; Meerum Terwogt et al, 1998; van Asperen et al, 1998; Bardelmeijer et al, 2004; Lagas et al, 2006; van Waterschoot et al, 2009; Hendrikx et al, 2013). $\mathrm{P}$-glycoprotein is a member of the ATP-binding cassette efflux transporter family and is expressed in multiple tissues such as intestine, liver and kidney, but also at the blood-brain barrier (BBB) (Gottesman and Ambudkar, 2001). P-glycoproteinmediated transport limits drug absorption across intestinal cells and brain penetration across the BBB. In enterocytes, P-gp pumps back absorbed taxanes into the intestinal lumen, whereas at the $\mathrm{BBB}$, taxanes are pumped back into the systemic circulation. In liver and kidney, P-gp increases drug excretion by active efflux transport into the bile and urine (Glaeser and Fromm, 2008).

CYP3A is a member of the CYP superfamily and CYP enzymes are responsible for most phase-I drug metabolism (Thelen and Dressman, 2009). CYP enzymes are mainly expressed in the liver, but some CYP members are also expressed in enterocytes. CYP3A is the most abundant CYP enzyme in liver and intestine, representing $40 \%$ and $80 \%$ of the total CYP enzymes expressed in each tissue, respectively (Paine et al, 2006). Docetaxel is primarily metabolised by enzymes of the CYP3A subfamily, whereas paclitaxel is metabolised by both CYP3A4 and CYP2C8 (Vaishampayan et al, 1999). In contrast to CYP3A, CYP2C8 is only expressed in liver cells (Paine et al, 2006).

Although docetaxel is a good P-gp substrate, transport of paclitaxel by $\mathrm{P}$-gp is even more efficient. In addition, paclitaxel metabolism is not solely CYP3A dependent. Therefore, it was assumed that oral bioavailability of paclitaxel was primarily limited by P-gp, and that of docetaxel primarily by CYP3A. However, in mice, complete $v s$ single knockout of $M d r 1 a / b$ and/or Cyp $3 a$ genes resulted in further increased plasma exposure of paclitaxel and docetaxel alike after oral administration, suggesting that both systems are important for oral availability of both taxanes (van Waterschoot et al, 2009; Hendrikx et al, 2013). The importance of CYP3A4 for paclitaxel metabolism was further supported by our finding that human CYP3A4 metabolises paclitaxel far more efficiently than the mouse Cyp3a enzymes (Hendrikx et al, 2013). Therefore, a promising strategy to boost the oral availability of these taxanes is combining oral formulations of paclitaxel or docetaxel with inhibitors of both P-gp and CYP3A4. In (pre) clinical studies, it has already been demonstrated that the area under the plasma concentration-time curves (AUC) after oral administration of paclitaxel and docetaxel can be strongly enhanced in both mice and humans by co-administration of the potent CYP3A4 inhibitor ritonavir (Bardelmeijer et al, 2002; Oostendorp et al, 2009; Koolen, 2011; Hendrikx et al, 2013). In addition, co-administration of the potent P-gp inhibitor elacridar results in increased oral plasma AUC of paclitaxel in mice and humans (Bardelmeijer et al, 2000; Malingre et al, 2001).

There are potential risks involved when the oral bioavailability of paclitaxel and docetaxel is increased by inhibition of metabolising enzymes and drug transporters. For instance, co-administration of oral elacridar in mice resulted in increased brain penetration of i.v. administered paclitaxel by inhibition of P-gp at the BBB (Kemper et al, 2003). Therefore, boosting oral uptake of taxanes using an oral P-gp inhibitor might increase the relative risk of CNS toxicity.
Furthermore, oral administration of docetaxel or paclitaxel to mice lacking both P-gp and Cyp3a resulted in substantially higher plasma levels than administration of the taxanes to mice lacking either P-gp or Cyp3a alone. Simultaneous inhibition of P-gp and CYP3A by drugs that are co-administered with orally administered taxanes may lead to further increased plasma levels of the taxanes and therefore an increased risk of side effects and toxicity in clinical practice.

In the present preclinical study, we examined whether we could substantially increase the oral availability of taxanes by simultaneous inhibition of P-gp and CYP3A using oral co-administration of elacridar and ritonavir, and to what extent this would affect P-gp transport at the $\mathrm{BBB}$.

\section{MATERIALS AND METHODS}

Drugs and chemicals. Paclitaxel, docetaxel, elacridar $\mathrm{HCl}$ and ritonavir were purchased from Sequoia Research Products (Oxford, UK). Drug-free lithium-heparinised human plasma was obtained from Bioreclamation LLC (New York, NY, USA). All other chemicals were of analytical grade and obtained from commercial sources.

Animals. In compliance with Dutch legislation, mice were housed and handled according to institutional guidelines, and approval of the local (NKI) animal care and use committee was obtained before the start of experiments. Mice were kept in a temperaturecontrolled environment with a 12-h light/12-h dark cycle and received a standard diet (AM-II, Hope Farms, Woerden, The Netherlands) and acidified water ad libitum. In this study, Сyp3a knockout mice with specific expression of human CYP3A4 in liver and intestine $\left(C y p 3 a^{-/-}\right.$Tg-3A4 $\left.4_{\mathrm{Hep} / \mathrm{Int}}\right)$ were used (van Herwaarden et al, 2007). The strain had a $>99 \%$ FVB genetic background. Cyp $3 a^{-1-} \mathrm{Tg}-3 \mathrm{~A} 4_{\mathrm{Hep} / \mathrm{Int}}$ mice were used as there is a species difference for paclitaxel in CYP3A substrate specificity or enzyme activity between endogenous murine Cyp3a and human CYP3A4 (Hendrikx et al, 2013). Experiments comparing paclitaxel PK in wild-type mice may therefore underestimate the impact of human CYP3A on paclitaxel pharmacokinetics in patients. The difference between species is minimised using Cyp $3 a^{-/-} \mathrm{Tg}-3 \mathrm{~A} 4_{\mathrm{Hep} / \mathrm{Int}}$ mice. A basic difference in docetaxel metabolite formation was not observed between human, wild-type mice and Cyp3a $3 a^{-1-} \mathrm{Tg}-3 \mathrm{~A} 4_{\mathrm{Hep} / \mathrm{Int}}$ mice (Hendrikx et al, 2013). In all experiments, male mice of 9-14 weeks of age were used.

In vivo analysis of plasma pharmacokinetics. Before the experiments, stock solutions containing $6 \mathrm{mg} \mathrm{ml}^{-1}$ paclitaxel, $6 \mathrm{mg} \mathrm{ml}^{-1}$ docetaxel, $15 \mathrm{mg} \mathrm{ml}^{-1}$ elacridar $\mathrm{HCl}, 7.5 \mathrm{mg} \mathrm{ml}^{-1}$ ritonavir or $15 \mathrm{mg} \mathrm{ml}^{-1}$ elacridar $\mathrm{HCl}$ and $7.5 \mathrm{mg} \mathrm{ml}^{-1}$ ritonavir in ethanol:polysorbate $80(1: 1, \mathrm{v} / \mathrm{v})$ were made and stored at $-20^{\circ} \mathrm{C}$. On the day of the experiments, stock solutions were diluted with water $(1: 5, \mathrm{v} / \mathrm{v})$ to obtain solutions for administration. Animals were fasted $2 \mathrm{~h}$ before oral drug administration to minimise variation in absorption. Paclitaxel and docetaxel were administered orally at a dose of $10 \mathrm{mg} \mathrm{kg}^{-1}$ of bodyweight, ritonavir was administered orally at a dose of $12.5 \mathrm{mg} \mathrm{kg}^{-1}$ of bodyweight, and elacridar was administered orally at a dose of $25 \mathrm{mg} \mathrm{kg}^{-1}$ of bodyweight. Oral administration was performed by gavage into the stomach using a blunt-ended needle. In case of co-administration with ritonavir, elacridar or ritonavir and elacridar, the booster(s) were orally administered $15 \mathrm{~min}$ before oral taxane administration.

Sample collection. For determining plasma pharmacokinetics, multiple blood samples $(\sim 50 \mu \mathrm{l})$ were collected from the tail vein at $15 \mathrm{~min}$ and at 1,2, 4, 8 and $24 \mathrm{~h}$ using heparinised capillary tubes (Oxford Labware, St Louis, MO, USA). All time point samples were derived from the same mouse. At the last time point of sequential 
sampling $(48 \mathrm{~h})$, blood was taken by cardiac puncture. Blood samples were centrifuged at ambient temperature at $8000 \mathrm{~g}$ for $5 \mathrm{~min}$ and subsequently plasma was collected. All samples were stored at $-20^{\circ} \mathrm{C}$ until analysis.

For brain accumulation studies, blood samples at $2 \mathrm{~h}$ were taken by cardiac puncture and brain tissue was isolated. Blood samples were centrifuged at ambient temperature at $8000 \mathrm{~g}$ for $5 \mathrm{~min}$ and subsequently plasma was collected. Brain tissue was homogenised in $1 \%$ bovine serum albumin. All samples were stored at $-20^{\circ} \mathrm{C}$ until analysis. Brain-to-plasma ratios at $t=2 \mathrm{~h}$ were calculated per mouse by dividing the brain concentration by the corresponding plasma concentration.

Bioanalytical analysis. Previously developed liquid chromatography assays coupled with tandem mass spectrometry detection (LC-MS/MS) were used to quantify paclitaxel (Stokvis et al, 2004) and docetaxel (Kuppens et al, 2005). Labelled structure analogues were used as internal standards. In summary, mouse plasma samples of $20 \mu \mathrm{l}$ were diluted with $180 \mu \mathrm{l}$ of human plasma. Human plasma was used for dilution of the samples as the concentrations in the undiluted mouse plasma were outside the calibration range, and also to mimic the calibration standards that were in human plasma. Brain samples were not diluted as concentrations were too low to quantify after dilution in some samples. To $200 \mu \mathrm{l}$ of diluted plasma sample or homogenised brain sample, $25 \mu$ l of internal standard working solution was added. Subsequently, the samples were mixed briefly, tertiary-butyl methyl ether was added and the samples were shaken for $10 \mathrm{~min}$ at 1250 r.p.m. The samples were centrifuged at $23000 \mathrm{~g}$, snap-frozen and the organic layer was collected. After evaporation of the organic layer, the samples were reconstituted with reconstitution solvent and an aliquot was injected into the LC-MS/MS system. Calibration standards in human plasma in a range of $0.25-$ $1000 \mathrm{ng} \mathrm{ml}^{-1}$ or $0.25-500 \mathrm{ng} \mathrm{ml}^{-1}$ were used for quantification of paclitaxel and docetaxel, respectively.

Pharmacokinetic calculations and statistical analysis. Pharmacokinetic parameters, including the AUCs, were calculated using the software package PK Solutions 2.0.2 (SUMMIT, Research Services, Ashland, $\mathrm{OH}, \mathrm{USA})$. The $\mathrm{AUC}_{0-\text { last time point was }}$ calculated by trapezoid calculation using observed data points. The total AUC extrapolated to infinity $\left(\mathrm{AUC}_{0-\mathrm{inf}}\right)$ was computed

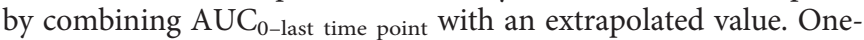
way ANOVA was used when multiple groups were compared and the Bonferroni post hoc correction was used to accommodate multiple testing. The two-sided unpaired Student's $t$-test was used when treatments or differences between two groups were compared. Data that did not show normal distribution were logtransformed to normalise the distribution of the data sets and enable statistical comparison. The Kolmogorov-Smirnov test was used to test for normal distribution. During all statistical analyses, differences in group sizes were considered in the calculations. Differences were considered statistically significant when $P<0.05$. All data are presented as geometric mean \pm s.d.

Addition of previously reported data. Previously, we published AUCs of paclitaxel after oral administration of $10 \mathrm{mg} \mathrm{kg}^{-1}$ paclitaxel with and without $12.5 \mathrm{mg} \mathrm{kg}^{-1}$ ritonavir to $C y p 3 a^{-1-}$ $\mathrm{Tg}-3 \mathrm{~A} 4_{\mathrm{Hep} / \mathrm{Int}}$ mice (five and seven animals were used, respectively) (Hendrikx et al, 2013). These data were compared with plasma concentrations after oral administration of $10 \mathrm{mg} \mathrm{kg}^{-1}$ paclitaxel with and without $12.5 \mathrm{mg} \mathrm{kg}^{-1}$ ritonavir obtained in this study (six and four animals were used, respectively). Previously obtained results were not statistically different from the results in the present study (data not shown). Therefore, these results were also used to decrease the number of animals needed for this study.
Comparison with previously reported data in knockout mice. To estimate the extent of P-gp inhibition by elacridar and Cyp3a inhibition by ritonavir, plasma exposure after chemical inhibition was compared with plasma exposure after complete knockout of P-gp or Cyp3A. Previously reported plasma $\mathrm{AUCs}_{0 \text {-inf }}$ after oral administration of $10 \mathrm{mg} \mathrm{kg}^{-1}$ paclitaxel (Hendrikx et al, 2013) or $10 \mathrm{mg} \mathrm{kg}^{-1}$ docetaxel (van Waterschoot et al, 2009) to mice lacking P-gp, Cyp3a or both were compared with $\mathrm{AUCs}_{0-\text { inf }}$ after chemical inhibition as obtained in this study. All plasma AUCs were normalised for their matching control group, and these relative plasma AUCs were used for comparison.

\section{RESULTS}

Paclitaxel exposure after oral co-administration with elacridar and/or ritonavir. To study the effect of the P-gp inhibitor elacridar and the CYP3A inhibitor ritonavir on oral bioavailability of paclitaxel, we orally administered $10 \mathrm{mg} \mathrm{kg}^{-1}$ paclitaxel to the CYP3A4-humanised Cyp3a $a^{-1-} \mathrm{Tg}-3 \mathrm{~A} 4_{\mathrm{Hep} / \text { Int }}$ mice and combined paclitaxel administration with $25 \mathrm{mg} \mathrm{kg}^{-1}$ elacridar and/or $12.5 \mathrm{mg} \mathrm{kg}^{-1}$ ritonavir.

Oral co-administration of paclitaxel and elacridar or paclitaxel and ritonavir resulted in increased plasma concentrations of paclitaxel (Figure 1). The area under the plasma concentrationtime curve from 0 extrapolated to infinity $\left(\mathrm{AUC}_{0 \text {-inf }}\right)$ was 10.7 -fold higher after co-administration with elacridar than after single paclitaxel administration $(P<0.001)$. These results in humanised mice are in line with the previously observed 6.6-fold increase in paclitaxel AUC after oral co-administration of paclitaxel and elacridar at the same dose to wild-type mice (Bardelmeijer et al, 2000). Co-administration of paclitaxel and ritonavir resulted in an increase in the $\mathrm{AUC}_{0-\text { inf }}$ of 2.5 -fold $(P<0.001)$. However, this boosting effect with ritonavir was clearly less than that of elacridar co-administration. Co-administration of paclitaxel with both elacridar and ritonavir together resulted in further increased plasma concentrations of paclitaxel (31.9-fold higher than single paclitaxel administration; $P<0.001)$. The increases in oral $\mathrm{AUC}_{0-\text { inf }}$ of paclitaxel after chemical inhibition with elacridar or ritonavir, alone or in combination, were comparable to the increases in oral $\mathrm{AUC}_{0-\mathrm{inf}}$ after complete genetic knockout of P-gp or Cyp3a, alone or in combination (Table 1). These data suggest that virtually complete inhibition of both $\mathrm{P}$-gp and CYP3A4 (intestinal and hepatic) was achieved with the combination elacridar and ritonavir.

Docetaxel exposure after oral co-administration with elacridar and/or ritonavir. Parallel to the paclitaxel experiments, we studied the effect of elacridar and/or ritonavir co-administration on the oral bioavailability of docetaxel. In the CYP3A4-humanised mouse model, we observed a 7.3-fold increase in $\mathrm{AUC}_{0 \text {-inf }}$ after oral administration of docetaxel and ritonavir when compared with $\mathrm{AUC}_{0-\text { inf }}$ after single docetaxel administration $(P<0.001$; Figure 2). Oral co-administration of docetaxel and elacridar resulted in a four-fold increase compared with single docetaxel administration $(P<0.001)$. The $\mathrm{AUC}_{0-\mathrm{inf}}$ of docetaxel after boosting with elacridar was not significantly different from the $\mathrm{AUC}_{0 \text {-inf }}$ after boosting with ritonavir $(P>0.05)$. As observed for paclitaxel, co-administration of docetaxel with both elacridar and ritonavir resulted in a further increase in $\mathrm{AUC}_{0 \text {-inf }}$ (37.4-fold higher than single docetaxel administration; $P<0.001)$. The increase in oral $\mathrm{AUC}_{0 \text {-inf }}$ of docetaxel after chemical inhibition with elacridar was comparable to the increase in oral $\mathrm{AUC}_{0 \text {-inf }}$ after complete genetic knockout of P-gp. However, the increase after chemical inhibition with ritonavir was modestly, but significantly $(P<0.01)$, lower than after complete genetic knockout of Cyp3a, and the same was true for combined CYP3A4 and P-gp 

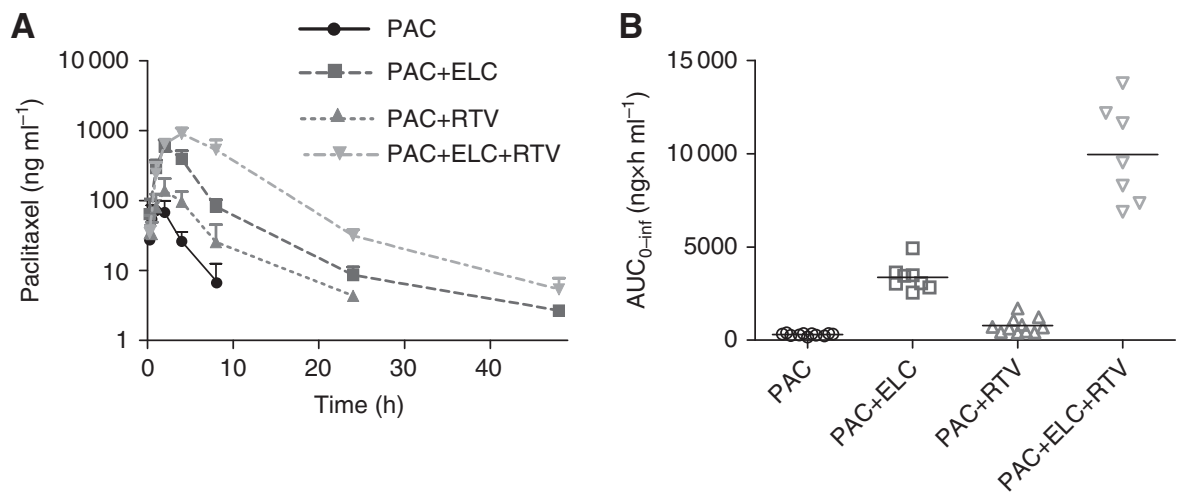

Figure 1. Panel A shows plasma concentration-time curves in Cyp3a $a^{-/-}$mice expressing human CYP3A4 in liver and intestine (Cyp3a ${ }^{-/-}$ $\left.\mathrm{Tg}-3 \mathrm{~A} 4_{\mathrm{Hep} / \mathrm{lnt}}\right)$ after oral administration of $10 \mathrm{mg} \mathrm{kg}^{-1}$ paclitaxel. Paclitaxel was administered alone or co-administered with $25 \mathrm{mg} \mathrm{kg}^{-1} \mathrm{oral}$ elacridar, $12.5 \mathrm{mg} \mathrm{kg}^{-1}$ oral ritonavir or both elacridar and ritonavir. Panel B shows the area under the plasma concentration-time curves from 0 extrapolated to infinity $\left(A \cup C_{0-i n f}\right)$. Data are presented as individual data points and lines represent the mean. Differences in $A U C_{0-i n f} b e t w e e n$ all groups were statistically significantly different $(P<0.001)$, unless stated otherwise (NS, $P>0.05)$. Values represent the means \pm s.d. In all, $8-11$ animals per group were used. Abbreviations: $E L C=$ elacridar; $P A C=$ paclitaxel; $R T V=$ ritonavir.

Table 1. Area under the plasma concentration-time curve of paclitaxel and docetaxel after oral administration of $10 \mathrm{mg} \mathrm{kg}^{-1} \mathrm{paclitaxel} \mathrm{or} 10 \mathrm{mg} \mathrm{kg}^{-1}$ docetaxel in Cyp3a ${ }^{-1-} \mathrm{Tg}-3 \mathrm{~A} 4_{\text {Hep/lnt }}$ mice

\begin{tabular}{|c|c|c|c|c|}
\hline & Control group ${ }^{a}$ & P-gp inhib./KO & CYP3A inhib./KO & CYP3A and P-gp inhib./KO \\
\hline \multicolumn{5}{|l|}{ Oral paclitaxel } \\
\hline $\begin{array}{l}\mathrm{AUC}_{0 \text {-inf }}\left(\mathrm{ng} \times \mathrm{h} \mathrm{ml}^{-1}\right) \text { after inhibition } \\
\text { Fold vs control } \\
\text { Number of animals }\end{array}$ & $\begin{array}{c}314 \pm 74 \\
1 \\
11\end{array}$ & $\begin{array}{c}3373 \pm 725 \\
10.7 \\
8\end{array}$ & $\begin{array}{c}780 \pm 412 \\
2.5 \\
11\end{array}$ & $\begin{array}{c}10002 \pm 2652 \\
31.9 \\
7\end{array}$ \\
\hline $\begin{array}{l}\mathrm{AUC}_{0 \text {-inf }}\left(\mathrm{ng} \times \mathrm{h} \mathrm{ml}^{-1}\right) \text { in KO mice } \\
\text { Fold vs control } \\
\text { Number of animals }\end{array}$ & $\begin{array}{c}320 \pm 224 \\
1 \\
10\end{array}$ & $\begin{array}{c}3954 \pm 825 \\
12.4 \\
5\end{array}$ & $\begin{array}{c}471 \pm 174 \\
1.5 \\
9\end{array}$ & $\begin{array}{c}8830 \pm 1999 \\
27.6 \\
5\end{array}$ \\
\hline \multicolumn{5}{|l|}{ Oral docetaxel } \\
\hline $\begin{array}{l}\mathrm{AUC}_{0-\text { inf }}\left(\mathrm{ng} \times \mathrm{h} \mathrm{ml}^{-1}\right) \text { after inhibition } \\
\text { Fold vs control } \\
\text { Number of animals }\end{array}$ & $\begin{array}{c}157 \pm 67 \\
1 \\
5\end{array}$ & $\begin{array}{c}626 \pm 182 \\
4.0 \\
5\end{array}$ & $\begin{array}{c}1146 \pm 281 \\
7.3 \\
5\end{array}$ & $\begin{array}{c}5869 \pm 2520 \\
37.4 \\
5\end{array}$ \\
\hline $\begin{array}{l}\mathrm{AUC}_{0 \text {-inf }}\left(\mathrm{ng} \times \mathrm{h} \mathrm{ml}^{-1}\right) \text { in KO mice } \\
\text { Fold vs control } \\
\text { Number of animals }\end{array}$ & $\begin{array}{c}228 \pm 130 \\
1 \\
6\end{array}$ & $\begin{array}{c}645 \pm 272 \\
2.8 \\
6\end{array}$ & $\begin{array}{c}2627 \pm 1011 \\
11.5 \\
6\end{array}$ & $\begin{array}{c}16466 \pm 2020 \\
72.2 \\
7\end{array}$ \\
\hline \multicolumn{5}{|c|}{ 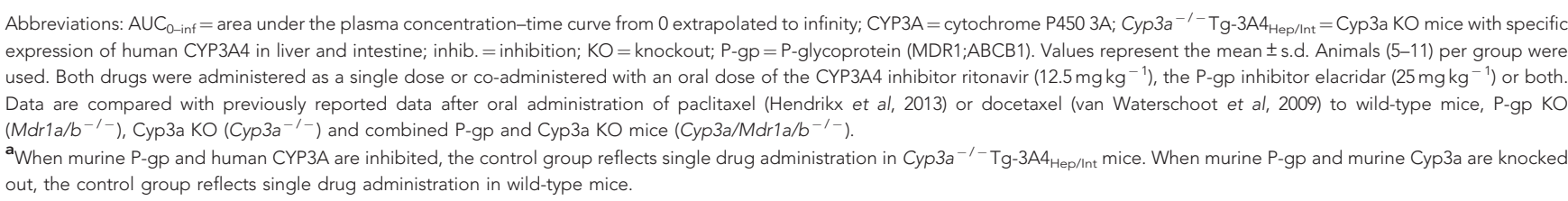 } \\
\hline
\end{tabular}

inhibition compared with full Cyp3a and P-gp knockout $(P<0.001$; Table 1). These data suggest that for docetaxel in the transgenic mice, the inhibition of intestinal and hepatic CYP3A4 by ritonavir was not entirely complete.

Brain concentrations of taxanes after oral co-administration with elacridar and/or ritonavir. As brain accumulation could potentially be increased after boosting of oral taxanes with a P-gp inhibitor, we measured brain concentrations $2 \mathrm{~h}$ after oral administration of paclitaxel or docetaxel, that is, roughly around the plasma $t_{\max }$. Two effects might occur: first, increased taxane brain concentrations simply as a consequence of the higher plasma levels of the taxanes; and second, a further, disproportionate increase in brain concentration relative to the plasma levels because of inhibition of $\mathrm{P}$-gp at the BBB, and/or possibly saturation of P-gp activity at the BBB because of the much higher plasma taxane levels. The second effects could result in poorly predictable alterations in CNS toxicity of the taxanes. As these effects are most likely to occur when plasma levels of both taxanes and inhibitors are high, we chose the 2 -h time point for sampling. Maximum plasma concentrations of docetaxel and paclitaxel are reached at 2-4h after oral administration. We did not measure plasma concentrations of the inhibitors in this experiment, but maximum plasma concentrations are reached in wild-type mice around $2 \mathrm{~h}$ after oral administration of elacridar (Bardelmeijer et al, 2000) or ritonavir (Supplementary Figure 1).

Brain concentrations of paclitaxel were significantly increased after co-administration with elacridar $(P<0.01 v s$ single paclitaxel administration), but not after co-administration with ritonavir $(P>0.05$; Figure $3 \mathrm{~B})$. Co-administration of paclitaxel with both 

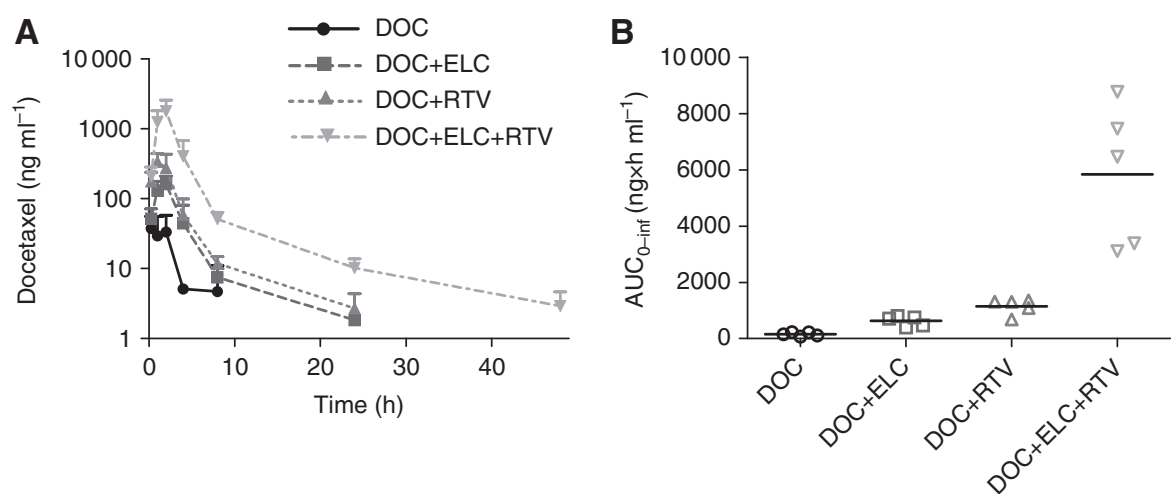

Figure 2. Panel A shows plasma concentration-time curves in Cyp3a ${ }^{-/-}$mice expressing human CYP3A4 in liver and intestine (Cyp3a-/$\mathrm{Tg}-3 \mathrm{~A} 4_{\mathrm{Hep} / \mathrm{lnt}}$ ) after oral administration of $10 \mathrm{mg} \mathrm{kg}^{-1}$ docetaxel. Docetaxel was administered alone or co-administered with $25 \mathrm{mg} \mathrm{kg}^{-1} \mathrm{oral}$ elacridar, $12.5 \mathrm{mg} \mathrm{kg}^{-1}$ oral ritonavir or both elacridar and ritonavir. Panel B shows the area under the plasma concentration-time curves from 0 extrapolated to infinity $\left(A \cup C_{0-i n f}\right)$. Data are presented as individual data points and lines represent the mean. Differences in $A \cup C_{0-i n f}$ between all groups were statistically significantly different $(P<0.001)$, unless stated otherwise $(N S, P>0.05)$. Values represent the means $\pm s$.d. Five animals per group were used. Abbreviations: $E L C=$ elacridar; $\mathrm{PAC}=$ paclitaxel; $\mathrm{RTV}=$ ritonavir.

A

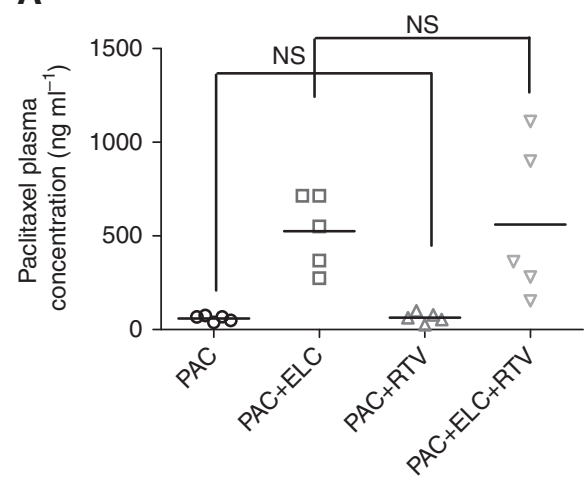

B

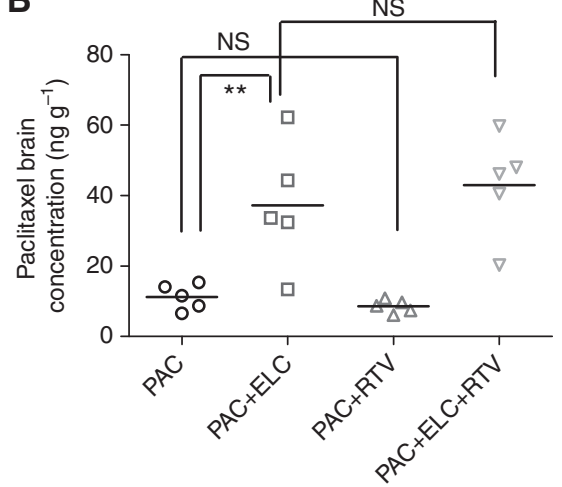

C

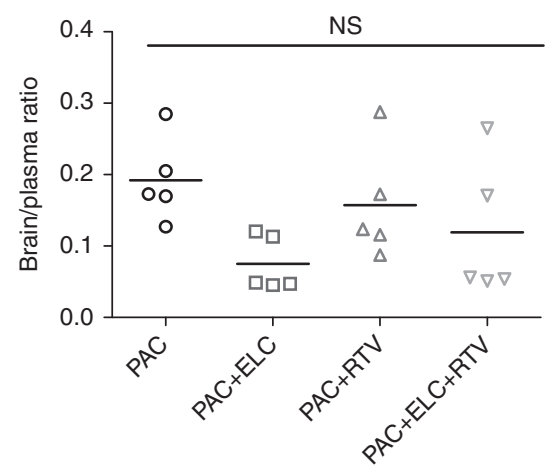

Figure 3. Plasma and brain concentrations of paclitaxel in Cyp3a $\mathrm{a}^{-/-}$mice expressing human CYP3A4 in liver and intestine $2 \mathrm{~h}$ after oral administration of $10 \mathrm{mg} \mathrm{kg}^{-1}$ paclitaxel. Paclitaxel was administered alone or co-administered with $25 \mathrm{mg} \mathrm{kg}^{-1} \mathrm{oral} \mathrm{elacridar,} 12.5 \mathrm{mg} \mathrm{kg}^{-1} \mathrm{oral}$ ritonavir or both elacridar and ritonavir. Panels reflect plasma concentrations (panel A), brain concentrations (panel B) or brain-to-plasma ratios (panel C). Data are presented as individual data points and lines represent the mean. Differences in plasma or brain concentrations between groups were statistically significantly different $(P<0.001$ ), unless stated otherwise (NS: not significant, $P>0.05$ or $* \star P<0.01$ ). Differences in brainto-plasma ratios between all groups were not statistically significant. Values represent the means \pm s.d. Five animals per group were used.

Abbreviations: $E L C=$ elacridar; $\mathrm{PAC}=$ paclitaxel; $\mathrm{RTV}=$ ritonavir.

elacridar and ritonavir resulted in a similar increase in brain concentrations as after co-administration of paclitaxel and elacridar $(P>0.05$ vs paclitaxel and elacridar administration; $P<0.001$ vs single paclitaxel administration). However, correcting for the increased plasma levels after boosting (Figure $3 \mathrm{~A}$ ), brainto-plasma ratios were not statistically different between the groups $(P>0.05$ for all comparisons; Figure $3 C)$. These data suggest that the relative brain accumulation of paclitaxel was not altered by elacridar and ritonavir co-administration, despite the substantially increased plasma levels of paclitaxel and the circulating elacridar levels.

Co-administration with elacridar also increased docetaxel brain concentrations $(P<0.01$ vs single docetaxel administration; Figure $4 \mathrm{~B})$. In contrast to paclitaxel brain concentrations, docetaxel brain concentrations were substantially increased after co-administration with ritonavir to comparable levels as seen after coadministration with elacridar $(P>0.05$ vs docetaxel and elacridar administration; $P<0.001$ vs single docetaxel administration), thus more or less following the pattern of effects of the inhibitors on docetaxel plasma concentrations. Brain concentrations of docetaxel were further increased after co-administration with both ritonavir and elacridar $(P<0.001$ vs single docetaxel administration). However, the increase in docetaxel brain concentrations was primarily caused by the increased plasma concentrations after boosting (Figure 4A), as brain-to-plasma ratios were not statistically significantly different between any of the treatment groups ( $P>0.05$ for all comparisons; Figure $4 \mathrm{C})$.

\section{DISCUSSION}

Our data with CYP3A4-humanised mice show that it is possible to markedly enhance the plasma AUC of oral paclitaxel and docetaxel (30- to 40 -fold) by orally co-administering elacridar and ritonavir. Each inhibitor contributed substantially to the overall AUC increase, although the contribution of elacridar was stronger for paclitaxel and that of ritonavir for docetaxel. Yet, at the same time, the relative brain accumulation of the taxanes (corrected for the increased plasma levels) was not increased. This indicates that neither the circulating elacridar levels, nor the increased plasma taxane levels were sufficient to substantially inhibit or saturate the 
A

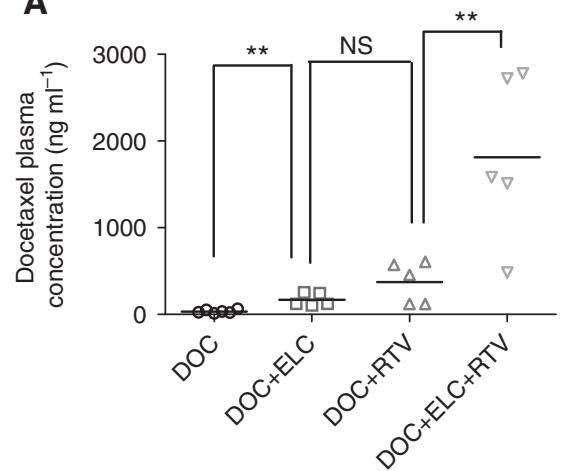

B

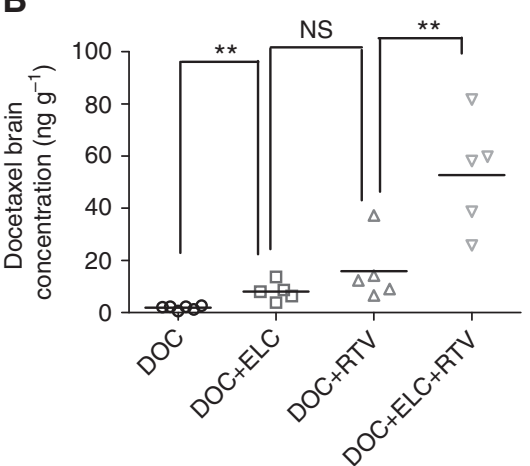

C

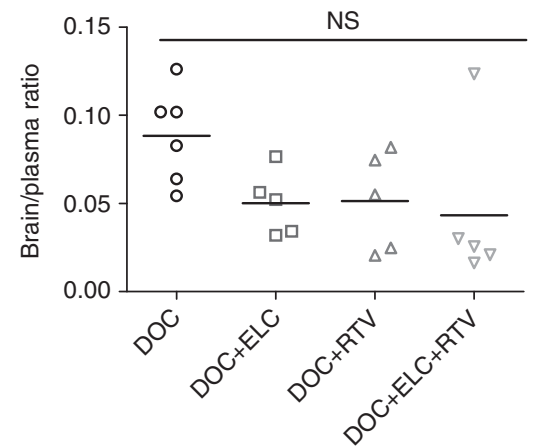

Figure 4. Plasma and brain concentrations of docetaxel in Cyp3a $\mathrm{a}^{-/-}$mice expressing human CYP3A4 in liver and intestine $2 \mathrm{~h}$ after oral administration of $10 \mathrm{mg} \mathrm{kg}^{-1}$ docetaxel. Docetaxel was administered alone or co-administered with $25 \mathrm{mg} \mathrm{kg}^{-1} \mathrm{oral} \mathrm{elacridar,} 12.5 \mathrm{mg} \mathrm{kg}^{-1} \mathrm{oral}$ ritonavir or both elacridar and ritonavir. Panels reflect plasma concentrations (panel A), brain concentrations (panel B) or brain-to-plasma ratios (panel C). Data are presented as individual data points and lines represent the mean. Differences in plasma or brain concentrations between groups were statistically significantly different $\left(P<0.001\right.$ ), unless stated otherwise (NS: not significant, $P>0.05$ or ${ }^{\star \star} P<0.01$ ). Differences in brainto-plasma ratios between all groups were not statistically significant. Values represent the means \pm s.d. Five to six animals per group were used. Abbreviations: $\mathrm{DOC}=$ docetaxel; $E L C=$ elacridar; $\mathrm{RTV}=$ ritonavir.

taxane export activity at the BBB. These data suggest that it may be possible to greatly enhance the oral availability of taxanes in patients by co-administration with oral elacridar and ritonavir, without invoking the risk of increased CNS toxicity of the taxanes.

To estimate the extent of P-gp inhibition by elacridar and CYP3A4 inhibition by ritonavir, plasma exposures after chemical inhibition were compared with plasma exposures after complete knockout of P-gp and/or Cyp3a (Table 1). Plasma AUCs -inf $_{0}$ of paclitaxel and docetaxel were comparable after complete knockout of P-gp and after chemical inhibition of P-gp by elacridar. This suggests that the intestinal and hepatic inhibition of P-gp was complete at the used dose of elacridar.

The plasma $\mathrm{AUCs}_{0-\text { inf }}$ of paclitaxel were similar after complete gene knockout of Cyp3a and inhibition of CYP3A4 by ritonavir, but the plasma $\mathrm{AUC}_{0 \text {-inf }}$ of docetaxel was slightly lower after ritonavir inhibition than upon Cyp3a knockout. The difference is not substantial (Table 1), but it can probably be attributed to incomplete inhibition of human CYP3A4 in the CYP3A4humanised mice at later time points, as the ritonavir concentrations likely drop considerably after a few hours. Although not tested in these mice, ritonavir levels in plasma of wild-type mice receiving $12.5 \mathrm{mg} \mathrm{kg}^{-1}$ oral ritonavir drop substantially after $2 \mathrm{~h}$ (Supplementary Figure 1), which may result in incomplete CYP3A4 inhibition at later time points. The effect may be more obvious for docetaxel than for paclitaxel because docetaxel metabolism is more strongly CYP3A dependent (van Waterschoot et al, 2009).

Previously reported data showed that complete knockout of both P-gp and Cyp3a resulted in higher plasma concentrations of orally applied taxanes than single knockout of P-gp or Cyp3a (van Waterschoot et al, 2009; Hendrikx et al, 2013). We show here that chemical inhibition of P-gp and CYP3A4 with both elacridar and ritonavir likewise further increased plasma concentrations of orally applied taxanes. In humans, oral formulations of paclitaxel and docetaxel were thus far tested with only one of these boosters. In patients, oral availability of paclitaxel is boosted by elacridar (Malingre et al, 2001) or ritonavir (Koolen, 2011) and oral availability of docetaxel is boosted by ritonavir (Oostendorp et al, 2009; Marchetti et al, 2012). Our results suggest that boosting of orally applied taxanes by both elacridar and ritonavir might further increase plasma exposure of taxanes in patients. Moreover, combined inhibition of P-gp and CYP3A4 may result in decreased interpatient and intrapatient variability in oral taxane pharmacokinetics. Xenobiotics, similar to other drugs, herbal derivatives or environmental pollutants can cause clinically relevant P-gp and CYP3A4 induction via Pregnane X receptor regulation (Wojnowski, 2004; Xu et al, 2005; di Masi et al, 2009). Complete inhibition of both P-gp and CYP3A4 in intestine and liver by elacridar and ritonavir can eliminate the effects of xenobiotic-related induction of these detoxifying proteins, and thereby decrease variability in taxane pharmacokinetics after oral administration. Polymorphisms of genes encoding for P-gp and CYP3A4 are currently not known to be related to variability in pharmacokinetics of i.v. administered taxanes (Bosch et al, 2006; Jabir et al, 2012), but after oral administration, polymorphisms of these genes can become more important. Interpatient variability in oral bioavailability of docetaxel is decreased when docetaxel is co-administered with inhibitors of CYP3A or P-gp (Stuurman et al, 2013). Not only polymorphisms, but also incomplete CYP3A4 inhibition by various other co-administered drugs might contribute to variable oral taxane plasma exposure (Koolen et al, 2010b; Quinney et al, 2013). Complete inhibition of CYP3A by ritonavir might eliminate this risk. It should be noted that, as P-gp and CYP3A4 act at both the intestinal and hepatic level, the risk of interpatient and intrapatient variability after oral administration of taxanes is likely higher than after i.v. administration of taxanes, as two potentially variable barriers need to be passed instead of one. This underscores the importance of reducing potential sources of variability by using effective CYP3A and P-gp inhibitors in oral taxane regimens.

Boosting orally applied taxanes with elacridar and ritonavir potentially increases the relative brain penetration of taxanes and would thereby increase the risk of brain toxicity, by either substantial inhibition of BBB P-gp by the circulating elacridar or saturation of BBB P-gp activity because of the highly increased plasma taxane levels, or a combination of both. We found here that brain concentrations were increased after co-administration of the taxanes with elacridar and ritonavir, but brain-to-plasma ratios were not. This indicates that the increased brain concentrations after oral co-administration of the taxanes with elacridar or ritonavir were merely a consequence of the increased plasma concentrations. Kemper et al (2003) showed a three-fold increase in brain-to-plasma ratios in wild-type mice at $1 \mathrm{~h}$ after administration of $10 \mathrm{mg} \mathrm{kg}^{-1}$ intravenously administered paclitaxel due to $25 \mathrm{mg} \mathrm{kg}^{-1}$ orally administered elacridar (brain-to-plasma ratios after administration of paclitaxel with and without elacridar were 0.08 and 0.22 , respectively). This three-fold increase was 
comparable with the increase in brain-to-plasma ratios as observed after i.v. administration of paclitaxel to P-gp knockout mice. Brain concentrations were not further increased when the elacridar dose was increased to $100 \mathrm{mg} \mathrm{kg}^{-1}$. Both findings suggest that $25 \mathrm{mg} \mathrm{kg}^{-1}$ oral elacridar can largely, if not completely, inhibit BBB P-gp activity. However, in our experiments, we observed no increase in brain-to-plasma ratios after oral co-administration of the same dose of paclitaxel and elacridar. This can most likely be explained by the initially far higher plasma levels of paclitaxel after i.v. administration compared with those after oral administration. When operating close to saturation, P-gp at the BBB will be more sensitive to partial inhibition (Kalvass et al, 2013). The absence of increased brain-to-plasma ratios in the experiments by Kemper et al (2003) at $4 \mathrm{~h}$ after administration of i.v. paclitaxel and oral elacridar (when plasma concentrations of paclitaxel are much lower) further supports this interpretation (brain-to-plasma ratios in wild-type mice after administration of paclitaxel with and without elacridar were 0.9 and 0.8 , respectively, whereas brain-toplasma ratios in knockout mice were 2.7 after i.v. administration of paclitaxel at this time point). Collectively, our data suggest that at modest plasma concentrations of paclitaxel (and presumably also docetaxel), P-gp in the BBB has little or no effect on the relative brain accumulation of taxanes.

\section{CONCLUSIONS}

Comparison of the results in our study with previously reported data obtained from oral administration of taxanes to knockout mice showed that orally administered elacridar and ritonavir at comparatively low doses can completely (for paclitaxel), or almost completely (for docetaxel) inhibit intestinal and hepatic P-gp and CYP3A4 activity.

We also demonstrated that co-administration of the taxanes with elacridar and ritonavir simultaneously resulted in a further increase in plasma levels of the taxanes. In contrast, relative brain accumulation of the taxanes was not affected after boosting with oral elacridar. Even at the highly increased plasma concentrations of taxanes after boosting with both elacridar and ritonavir, relative brain accumulation was still similar as seen after boosting with elacridar, or even in otherwise untreated CYP3A4-humanised animals.

We therefore believe that it will be worthwhile testing whether simultaneous inhibition of P-gp and CYP3A may provide a relatively safe strategy to boost plasma exposure of orally applied taxanes in patients, as relative brain exposure is unlikely to be higher than that in the currently used i.v. schedules.

\section{CONFLICT OF INTEREST}

The research group of AHS receives revenue from commercial distribution of some of the mouse strains used in this study. JHMS and JHB are inventors on patents on the application of oral taxane formulations. The remaining authors declare no conflict of interest.

\section{REFERENCES}

Bardelmeijer HA, Beijnen JH, Brouwer KR, Rosing H, Nooijen WJ, Schellens JH, van Tellingen O (2000) Increased oral bioavailability of paclitaxel by GF120918 in mice through selective modulation of P-glycoprotein. Clin Cancer Res 6: 4416-4421.

Bardelmeijer HA, Ouwehand M, Beijnen JH, Schellens JH, van Tellingen O (2004) Efficacy of novel P-glycoprotein inhibitors to increase the oral uptake of paclitaxel in mice. Invest New Drugs 22: 219-229.
Bardelmeijer HA, Ouwehand M, Buckle T, Huisman MT, Schellens JH, Beijnen JH, van Tellingen O (2002) Low systemic exposure of oral docetaxel in mice resulting from extensive first-pass metabolism is boosted by ritonavir. Cancer Res 62: 6158-6164.

Bosch TM, Meijerman I, Beijnen JH, Schellens JH (2006) Genetic polymorphisms of drug-metabolising enzymes and drug transporters in the chemotherapeutic treatment of cancer. Clin Pharmacokinet 45: 253-285.

di Masi A, De Marinis E, Ascenzi P, Marino M (2009) Nuclear receptors CAR and PXR: Molecular, functional, and biomedical aspects. Mol Aspects Med 30: $297-343$.

Glaeser H, Fromm MF (2008) Animal models and intestinal drug transport. Exp Opin Drug Metab Toxicol 4: 347-361.

Gligorov J, Lotz JP (2004) Preclinical pharmacology of the taxanes: implications of the differences. Oncologist 9(Suppl 2): 3-8.

Gottesman MM, Ambudkar SV (2001) Overview: ABC transporters and human disease. J Bioenerg Biomembr 33: 453-458.

Hendrikx JJ, Lagas JS, Rosing H, Schellens JH, Beijnen JH, Schinkel AH (2013) $\mathrm{P}$-glycoprotein and cytochrome $\mathrm{P} 450$ 3A act together in restricting the oral bioavailability of paclitaxel. Int J Cancer 132: 2439-2447.

Jabir RS, Naidu R, Annuar MA, Ho GF, Munisamy M, Stanslas J (2012) Pharmacogenetics of taxanes: impact of gene polymorphisms of drug transporters on pharmacokinetics and toxicity. Pharmacogenomics 13: 1979-1988.

Jiang H, Tao W, Zhang M, Pan S, Kanwar JR, Sun X (2010) Low-dose metronomic paclitaxel chemotherapy suppresses breast tumors and metastases in mice. Cancer Invest 28: 74-84.

Kalvass JC, Polli JW, Bourdet DL, Feng B, Huang SM, Liu X, Smith QR, Zhang LK, Zamek-Gliszczynski MJ (2013) Why clinical modulation of efflux transport at the human blood-brain barrier is unlikely: the ITC evidence-based position. Clin Pharmacol Ther 94: 80-94.

Kemper EM, van Zandbergen AE, Cleypool C, Mos HA, Boogerd W, Beijnen JH, van Tellingen $O$ (2003) Increased penetration of paclitaxel into the brain by inhibition of P-Glycoprotein. Clin Cancer Res 9: 2849-2855.

Koolen SL. Intravenous-to-oral switch in anticancer chemotherapy. Focus on taxanes and gemcitabine. Dissertation, Utrecht University: Utrecht, The Netherlands, 2011.

Koolen SL, Beijnen JH, Schellens JHM (2010a) Intravenous-to-oral switch in anticancer chemotherapy: a focus on docetaxel and paclitaxel. Clin Pharmacol Ther 87: 126-129.

Koolen SL, Oostendorp RL, Beijnen JH, Schellens JHM, Huitema AD (2010b) Population pharmacokinetics of intravenously and orally administered docetaxel with or without co-administration of ritonavir in patients with advanced cancer. Br J Clin Pharmacol 69: 465-474.

Kuppens IE, van Maanen MJ, Rosing H, Schellens JHM, Beijnen JH (2005) Quantitative analysis of docetaxel in human plasma using liquid chromatography coupled with tandem mass spectrometry. Biomed Chromatogr 19: 355-361.

Lagas JS, Vlaming ML, van Tellingen O, Wagenaar E, Jansen RS, Rosing H, Beijnen JH, Schinkel AH (2006) Multidrug resistance protein 2 is an important determinant of paclitaxel pharmacokinetics. Clin Cancer Res 12: 6125-6132.

Malingre MM, Beijnen JH, Rosing H, Koopman FJ, Jewell RC, Paul EM, ten Bokkel Huinink WW, Schellens JH (2001) Co-administration of GF120918 significantly increases the systemic exposure to oral paclitaxel in cancer patients. Br J Cancer 84: 42-47.

Marchetti S, Stuurman FE, Koolen SL, Moes JJ, Hendrikx JJ, Thijssen B, Huitema AD, Nuijen B, Rosing H, Keessen M, Voest EE, Mergui-Roelvink M, Beijnen JH, Schellens JH (2012) Phase I study of weekly oral docetaxel (ModraDoc001) plus ritonavir in patients with advanced solid tumors. ASCO Meeting Abstracts 30: 2550.

Meerum Terwogt JM, Beijnen JH, ten Bokkel Huinink WW, Rosing H, Schellens JH (1998) Co-administration of cyclosporin enables oral therapy with paclitaxel. Lancet 352: 285.

Oostendorp RL, Huitema A, Rosing H, Jansen RS, Ter Heine R, Keessen M, Beijnen JH, Schellens JHM (2009) Coadministration of ritonavir strongly enhances the apparent oral bioavailability of docetaxel in patients with solid tumors. Clin Cancer Res 15: 4228-4233.

Paine MF, Hart HL, Ludington SS, Haining RL, Rettie AE, Zeldin DC (2006) The human intestinal cytochrome P450 'pie'. Drug Metab Dispos 34: $880-886$.

Quinney SK, Malireddy SR, Vuppalanchi R, Hamman MA, Chalasani N, Gorski JC, Hall SD (2013) Rate of onset of inhibition of gut-wall and hepatic CYP3A by clarithromycin. Eur J Clin Pharmacol 69: 439-448. 
Schellens JHM, Malingre MM, Kruijtzer CM, Bardelmeijer HA, van Tellingen O, Schinkel AH, Beijnen JH (2000) Modulation of oral bioavailability of anticancer drugs: from mouse to man. Eur J Pharm Sci 12: 103-110.

Sparreboom A, van Asperen J, Mayer U, Schinkel AH, Smit JW, Meijer DK, Borst P, Nooijen WJ, Beijnen JH, van Tellingen O (1997) Limited oral bioavailability and active epithelial excretion of paclitaxel (Taxol) caused by P-glycoprotein in the intestine. Proc Natl Acad Sci USA 94: 2031-2035.

Stokvis E, Ouwehand M, Nan LG, Kemper EM, van Tellingen O, Rosing H, Beijnen JH (2004) A simple and sensitive assay for the quantitative analysis of paclitaxel in human and mouse plasma and brain tumor tissue using coupled liquid chromatography and tandem mass spectrometry. J Mass Spectrom 39: 1506-1512.

Stuurman FE, Nuijen B, Beijnen JH, Schellens JH (2013) Oral anticancer drugs: mechanisms of low bioavailability and strategies for improvement. Clin Pharmacokinet 52: 399-414.

Thelen K, Dressman JB (2009) Cytochrome P450-mediated metabolism in the human gut wall. J Pharm Pharmacol 61: 541-558.

Vaishampayan U, Parchment RE, Jasti BR, Hussain M (1999) Taxanes: an overview of the pharmacokinetics and pharmacodynamics. Urology 54 : $22-29$.

van Asperen J, van Tellingen O, Sparreboom A, Schinkel AH, Borst P, Nooijen WJ, Beijnen JH (1997) Enhanced oral bioavailability of paclitaxel in mice treated with the P-glycoprotein blocker SDZ PSC 833. Br J Cancer 76: 1181-1183.

van Asperen J, van Tellingen $\mathrm{O}$, van der Valk MA, Rozenhart M, Beijnen JH (1998) Enhanced oral absorption and decreased elimination of paclitaxel in mice cotreated with cyclosporin A. Clin Cancer Res 4: 2293-2297.

van Herwaarden AE, Wagenaar E, van der Kruijssen CM, van Waterschoot RA, Smit JW, Song JY, van der Valk MA, van Tellingen O, van der Hoorn JW, Rosing H, Beijnen JH, Schinkel AH (2007) Knockout of cytochrome P450 $3 \mathrm{~A}$ yields new mouse models for understanding xenobiotic metabolism. J Clin Invest 117: 3583-3592.

van Waterschoot RA, Lagas JS, Wagenaar E, van der Kruijssen CM, van Herwaarden AE, Song JY, Rooswinkel RW, van Tellingen O, Rosing H, Beijnen JH, Schinkel AH (2009) Absence of both cytochrome P450 3A and $\mathrm{P}$-glycoprotein dramatically increases docetaxel oral bioavailability and risk of intestinal toxicity. Cancer Res 69: 8996-9002.

Wojnowski L (2004) Genetics of the variable expression of CYP3A in humans. Ther Drug Monit 26: 192-199.

Wu H, Xin Y, Zhao J, Sun D, Li W, Hu Y, Wang S (2011) Metronomic docetaxel chemotherapy inhibits angiogenesis and tumor growth in a gastric cancer model. Cancer Chemother Pharmacol 68: 879-887.

Xu C, Li CY, Kong AN (2005) Induction of phase I, II and III drug metabolism/transport by xenobiotics. Arch Pharm Res 28: 249-268.

This work is published under the standard license to publish agreement. After 12 months the work will become freely available and the license terms will switch to a Creative Commons AttributionNonCommercial-Share Alike 3.0 Unported License.

Supplementary Information accompanies this paper on British Journal of Cancer website (http://www.nature.com/bjc) 